\title{
Tertiary Hyperparathyroidism
}

National Cancer Institute

\section{Source}

National Cancer Institute. Tertiary Hyperparathyroidism. NCI Thesaurus. Code C114821.

An overproduction of parathyroid hormone that is autonomous and often associated with chronic secondary hyperparathyroidism. 